\title{
Uso de aminoquinolinas (Cloroquina e Hidroxicloroquina) no tratamento da
} COVID-19: uma revisão sistemática

\author{
Use of aminoquinolines (Chloroquine and Hydroxychloroquine) in the treatment of COVID-19: a \\ systematic review
}

Uso de aminoquinolinas (Cloroquina e Hidroxicloroquina) en el tratamiento de COVID-19: una revisión sistemática

Luan Victor Almeida Lima ORCID: https://orcid.org/0000-0002-2145-009X Hospital São José de Doenças Infecciosas, Brasil Centro Universitário Christus, Brasil E-mail: luanvictor.al@gmail.com

Filipe Saboya Santos ORCID: https://orcid.org/0000-0002-5416-4524 Centro Universitário Christus, Brasil

E-mail: filipesaboya98@gmail.com

Nataly Abreu Alves

ORCID: https://orcid.org/0000-0001-7021-8820 Centro Universitário Christus, Brasil E-mail: nataly_abreu123@hotmail.com

Sabrina Sales Alves

ORCID: https://orcid.org/0000-0002-4725-7052 Centro Universitário Christus, Brasil E-mail: sabrina.sales9@hotmail.com

Iury Magalhães Dutra de Melo ORCID: https://orcid.org/0000-0003-4763-1814 Centro Universitário Christus, Brasil E-mail: iurydutra@gmail.com

Tereza de Jesus Pinheiro Gomes Bandeira ORCID: https://orcid.org/0000-0002-1098-9380 Centro Universitário Christus, Brasil E-mail: bandtereza@gmail.com

\begin{abstract}
Resumo
A pandemia da COVID-19, causada pelo vírus SARS-COV-2, é uma doença infecciosa que até o momento atual não há um tratamento eficaz que reduza a mortalidade dos pacientes. A Hidroxicloroquina (HCQ) e a Cloroquina (CQ) são fármacos derivados da aminoquinolina usados na prevenção e tratamento da malária. Inicialmente, as aminoquinolinas foram relatadas como eficazes no combate ao SARS-COV-2 devido aos efeitos anti-inflamatórios e antivirais, entretanto, vários trabalhos foram publicados na literatura, abordando a eficácia, levando a resultados contraditórios. Ademais, não há, até o presente momento, evidências concretas que apoiem o seu uso, assim como, há um escasso número de ensaios clínicos que mostrem evidências da eficácia desses medicamentos. Por isso, o presente estudo possui o objetivo de avaliar a eficácia da HCQ e CQ no tratamento de pacientes com COVID-19, por meio da realização de uma revisão sistemática dos principais artigos envolvendo pacientes com COVID-19 e o uso de HCQ e CQ. Uma revisão sistemática foi realizada tendo como base pesquisa nos bancos de dados PubMed e EMBASE para encontrar artigos que forneçam informações sobre a eficácia e segurança das formulações relacionadas às aminoquinolinas em pacientes com pneumonia por SARS-CoV-2. A pesquisa inicial identificou em total de 162 artigos, havendo 14 elegíveis, sendo que 13 destes não encontraram diferença significativa.
\end{abstract}

Palavras-chave: COVID-19; SARS-COV-2; Cloroquina; Hidroxicloroquina.

\section{Abstract}

The COVID-19 pandemic, caused by the SARS-COV-2 virus, is an infectious disease that to date there is no effective treatment to reduce patient mortality. Hydroxychloroquine (HCQ) and Chloroquine (CQ) are aminoquinoline-derived drugs used in the prevention and treatment of malaria. Initially, aminoquinolines were reported as effective in combating SARS-COV-2 due to their anti-inflammatory and antiviral effects, however, several studies were published in the literature, addressing their efficacy, leading to contradictory results. Furthermore, there is, to date, no concrete evidence 
to support their use, as well as, there is a small number of clinical trials that show evidence of the effectiveness of these drugs. Therefore, the present study aims to assess the effectiveness of HCQ and CQ in the treatment of patients with COVID-19, through a systematic review of the main articles involving patients with COVID-19 and the use of HCQ and CQ. A systematic review was performed based on a search in the PubMed and EMBASE databases to find articles that provide information on the efficacy and safety of formulations related to aminoquinolines in patients with SARS CoV-2 pneumonia. The initial search identified a total of 162 articles, with 14 eligible, and 13 of these found no significant difference.

Keywords: COVID-19; SARS-COV-2; Chloroquine; Hydroxychloroquine.

\section{Resumen}

La pandemia COVID-19, provocada por el virus SARS-COV-2, es una enfermedad infecciosa que hasta la fecha no existe un tratamiento eficaz para reducir la mortalidad de los pacientes. La hidroxicloroquina (HCQ) y la cloroquina (CQ) son fármacos derivados de la aminoquinolina que se utilizan en la prevención y el tratamiento de la malaria. Inicialmente, se informó que las aminoquinolinas eran efectivas para combatir el SARS-COV-2 debido a sus efectos antiinflamatorios y antivirales, sin embargo, se publicaron varios estudios en la literatura, que abordaron su eficacia, lo que condujo a resultados contradictorios. Además, hasta la fecha, no hay evidencia concreta que apoye su uso, así como, existe una pequeña cantidad de ensayos clínicos que muestran evidencia de la efectividad de estos fármacos. Por tanto, el presente estudio tiene como objetivo evaluar la eficacia de HCQ y CQ en el tratamiento de pacientes con COVID19, mediante una revisión sistemática de los principales artículos que involucran a pacientes con COVID-19 y el uso de HCQ y CQ. Se realizó una revisión sistemática basada en una búsqueda en las bases de datos PubMed y EMBASE para encontrar artículos que brinden información sobre la eficacia y seguridad de las formulaciones relacionadas con las aminoquinolinas en pacientes con neumonía por SARS-CoV-2. La búsqueda inicial identificó un total de 162 artículos, con 14 elegibles, y 13 de estos no encontraron diferencias significativas.

Palabras clave: COVID-19; SARS-COV-2; Cloroquina; Hidroxicloroquina.

\section{Introdução}

A doença causada pelo novo coronavírus, a COVID-19 (do inglês, Coronavirus disease-2019) é causada pelo vírus SARS-CoV-2 (Severe Acute Respiratory Syndrome Coronavirus-2), de fonte zoonótica (Recovery Collaborative Group, 2021). A doença COVID-19 surgiu em dezembro de 2019 na cidade de Wuhan na China e foi notificada pela OMS como uma pandemia em 11 de março de 2020 (UNA-SUS, 2021). Até 14 de junho de 2021, cerca de 176 milhões de casos de COVID-19 e 3,8 milhões de mortes foram relatados em todo o mundo constituindo, atualmente em emergência em saúde pública de importância internacional (WHO, 2020; WHO, 2021). O vírus SARS-CoV-2 é um membro da família Coronavirus, uma família que foi anteriormente responsável pela Síndrome Respiratória Aguda Grave (SARS - do inglês, Severe Acute Respiratory Syndrome) em 2002 e pela Síndrome Respiratória do Oriente Médio (MERS - do inglês, Middle East Respiratory Syndrome) em 2012 (Ghazy et al., 2020). As características fisiopatológicas de COVID-19 grave são representadas por um processo pneumônico agudo com extensa opacidade radiológica e, na autópsia, dano alveolar difuso, infiltrados inflamatórios e trombose microvascular. Até agora, não há tratamento eficaz para COVID-19. A HCQ e CQ são fármacos usados na prevenção e tratamento de malária. Entre outras aplicações, pode ser usada no tratamento de artrite reumatoide, lúpus eritematoso e porfiria cutânea tardia. É administrada por via oral. Como antimaláricos agem interferindo com o DNA e também vacúolos digestivos do parasita.

Os efeitos da HCQ e CQ sobre determinadas famílias virais, incluindo a dos Coranavirus, foi publicada pela primeira vez em 2006 por Savarino et al., e em seguida em 2013 por Yan et al. Apesar destes estudos preliminares, meses antes de declarada a pandemia de COVID-19, era notória a escassez de ensaios clínicos randomizados que evidenciassem a eficácia do tratamento com HCQ no combate à COVID-19. Na verdade, as pesquisas vêm demonstrando o surgimento de graves e fatais efeitos indesejáveis, incluindo problemas cardíacos (Conselho Nacional de Saúde, 2021). A CQ foi inicialmente relatada como eficaz contra o SARS-CoV-2, seguida pela HCQ (Geleris et al., 2020). O SARS-CoV-2 é conhecido por se ligar a células humanas por meio do receptor da ACE2 (Devaux et al., 2020). Estudos in vitro mostraram que CQ e HCQ causam glicosilação de células produtoras de receptor ACE2, tornando-as refratárias à infecção por SARS-CoV-2. Isso torna os fármacos possíveis 
atuantes no tratamento e até na profilaxia contra o COVID-19. Nos últimos meses, vários trabalhos foram publicados na literatura, abordando a eficácia da HCQ em pacientes com COVID-19, levando a resultados contraditórios. As aminoquinolinas (cloroquina e hidroxicloroquina) são recomendadas no tratamento da malária e de doenças reumáticas, e foram sugeridas como tratamento para COVID-19 com base em efeitos anti-inflamatórios e antivirais (Geleris et al., 2020). A CQ é utilizada em todo o mundo há mais de 70 anos e faz parte da lista de medicamentos essenciais da Organização Mundial da Saúde (OMS). Ademais, é um medicamento de custo acessível e apresentou um perfil de segurança quando utilizado para os fins acima citados (Cortegiani et al., 2020). Porém, apesar de terem sido utilizadas em serviços de saúde no Brasil e no mundo para o tratamento do COVID19, não há, até o presente momento, evidências concretas que apoiam o seu uso. Como também, há um escasso número de ensaios clínicos que mostrem evidências da eficácia desses medicamentos. Por isso, o presente estudo possui o objetivo de avaliar a eficácia das aminoquinolinas no tratamento de pacientes com COVID-19, bem como correlacionar o uso das mesmas com a mortalidade de pacientes com COVID-19. Desta forma, o estudo será por meio da realização de uma revisão sistemática dos principais artigos envolvendo pacientes com COVID-19 e o uso de aminoquinolinas.

\section{Metodologia}

\subsection{Desenho do Estudo}

Uma revisão sistemática foi realizada tendo como base pesquisa nos bancos de dados PubMed e EMBASE para encontrar artigos que forneçam informações sobre a eficácia e segurança das formulações relacionadas à cloroquina e à hidroxicloroquina em pacientes com pneumonia por SARS-CoV-2 e artigos que descrevem estudos in vitro relacionados. Dependendo da análise dos resultados será avaliada a possibilidade de realização de uma metanálise.

\subsection{Pergunta norteadora}

As aminoquinolinas (cloroquina e hidroxicloroquina) são eficazes no tratamento da COVID-19 com redução da mortalidade?

\subsection{Critérios de inclusão}

Trabalhos publicados sobre o tratamento de pacientes adultos com as aminoquinolinas (cloroquina e hidroxicloroquina).

\subsection{Critérios de exclusão}

Estudos que não foram feitos exclusivamente em pacientes com COVID-19; alterações no tratamento ao longo do tempo e estudos-piloto; editoriais/avaliações/cartas/comentários; e estudos publicados em idiomas que não o português, o espanhol ou o inglês.

\subsection{Métodos}

Estratégia de pesquisa: (((("chloroquin"[All Fields] OR "chloroquine"[MeSH Terms]) OR "chloroquine"[All Fields]) OR "chloroquine s"[All Fields]) OR "chloroquines"[All Fields]) OR ("hydroxychloroquine"[MeSH Terms] OR "hydroxychloroquine"[All Fields])) AND (((("COVID-19"[All Fields] OR (("severe acute respiratory syndrome coronavirus 2"[Supplementary Concept] OR "severe acute respiratory syndrome coronavirus 2"[All Fields]) OR "sars cov 2"[All Fields])) OR (("severe acute respiratory syndrome coronavirus 2"[Supplementary Concept] OR "severe acute respiratory syndrome coronavirus 2"[All Fields]) OR "2019 ncov"[All Fields])) OR (("coronavirus"[MeSH Terms] OR "coronavirus"[All Fields]) OR "coronaviruses"[All Fields])) OR (((("pneumonia"[MeSH Terms] OR "pneumonia"[All Fields]) OR "pneumoniae"[All Fields]) 
OR "pneumonias"[All Fields]) OR "pneumoniae s"[All Fields])) (Cortegiane et al., 2020).

Coleta de dados: Dois pesquisadores independentes coletaram dados sobre o desenho do estudo, a qualidade metodológica, o risco de viés, o perfil do paciente e os desfechos de eficácia e segurança com um formulário eletrônico elaborado utilizando o Excel®. As discordâncias serão resolvidas por consenso. A caracterização da amostra está apresentada na imagem 1.

Imagem 1 - Caracterização da amostra.

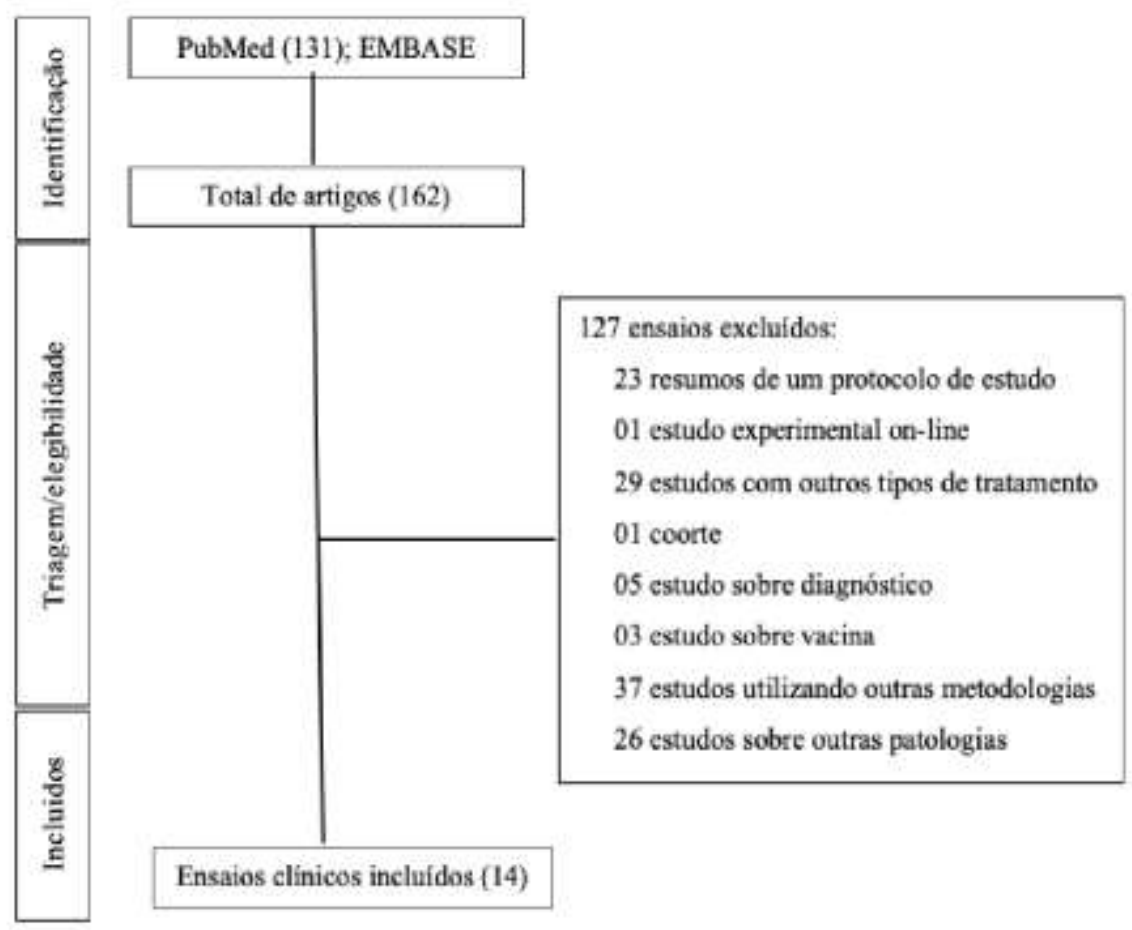

Fonte: Autores.

\section{Resultados}

A pesquisa inicial identificou 131 do banco de dados PubMed e numa segunda pesquisa realizada, desta vez no banco de dados EMBASE, foram identificados 31 trabalhos. Do total de 162 trabalhos nas duas pesquisas, após a triagem de títulos e resumos e remoção de duplicatas, 127 foram excluídos. Entre os trabalhos excluídos, havia 32 resumos de um protocolo de estudo, um estudo experimental online, 35 referentes a outros tratamentos, uma coorte, cinco referentes a diagnóstico, três referentes a vacinação, 45 sobre outras metodologias e 26 sobre outras patologias. Ao final, avaliamos 14 ensaios clínicos em texto completo que foram selecionados para constituir o escopo da revisão sistemática. Na tabela 1 estão relacionados os dados dos trabalhos analisados, por autor/título, metodologia, amostra, dosagem de HCQ, desfecho e resultado/conclusão. Dos 14 trabalhos apresentados na referida tabela, foram assim distribuídos: 5 ensaios clínicos controlados randomizados, 4 ensaios clínicos controlados, randomizados, duplo-cego, 3 ensaios clínicos controlados, randomizados, abertos, 1 ensaio clínico aberto não randomizado e 1 Estudo randomizado, caso controle. 
Tabela 1 - Características dos ensaios clínicos incluídos neste estudo.

\begin{tabular}{|c|c|c|c|c|c|}
\hline Autor/Título & Metodologia & Amostra & Dose & Desfecho & Resultado/Conclusão \\
\hline $\begin{array}{l}\text { Boulware et al. } \\
\text { A Randomized Trial } \\
\text { of } \\
\text { Hydroxychloroquine } \\
\text { as Postexposure } \\
\text { Prophylaxis for Covid- } \\
19\end{array}$ & $\begin{array}{l}\text { Ensaio clínico } \\
\text { controlado, } \\
\text { randomizado, } \\
\text { duplo-cego }\end{array}$ & $\begin{array}{l}821 \text { participantes } \\
\text { assintomáticos. } \\
87,6 \% \text { dos participantes } \\
(719 \text { de } 821) \text { relataram } \\
\text { uma exposição de alto } \\
\text { risco a um contato } \\
\text { confirmado com Covid- } \\
19 .\end{array}$ & $\begin{array}{l}800 \text { mg uma vez, } \\
\text { seguido por } 600 \\
\text { mg em } 6 \text { a } 8 \\
\text { horas, depois } 600 \\
\text { mg por dia por } 4 \\
\text { dias adicionais }\end{array}$ & $\begin{array}{l}\text { Desfecho primário - } \\
\text { doença sintomática } \\
\text { confirmada por um ensaio } \\
\text { molecular positivo ou, se o } \\
\text { teste não estiver } \\
\text { disponível, sintomas } \\
\text { relacionados a Covid-19. } \\
\text { Desfechos secundários } \\
\text { incluíram a incidência de } \\
\text { hospitalização por Covid- } \\
19 \text { ou morte, a incidência } \\
\text { de infecção por SARS- } \\
\text { CoV-2 confirmada por } \\
\text { PCR, a incidência de } \\
\text { sintomas de Covid-19. }\end{array}$ & $\begin{array}{l}414 \text { pacientes usaram HCQ } \\
\text { - } 49 \text { tiveram COVID } \\
407 \text { usaram Placebo - } 58 \\
\text { tiveram COVID intervalo } \\
\text { de confiança de } 95 \%,-7,0 \\
\text { a } 2,2 ; \\
\text { CONCLUSÃO: } \\
\text { p=0,35 } \\
\text { Não houve diferença } \\
\text { significativa }\end{array}$ \\
\hline $\begin{array}{l}\text { Huang et al. } \\
\text { Treating COVID-19 } \\
\text { with Chloroquine }\end{array}$ & $\begin{array}{l}\text { Estudo } \\
\text { randomizado, } \\
\text { caso controle }\end{array}$ & $\begin{array}{l}\text { Pacientes hospitalizados } \\
\text { com Covid-19 triados } 82 \\
\text { Pacientes elegíveis } 22\end{array}$ & $\begin{array}{l}\text { Cloroquina } 500 \\
\text { mg por via oral } \\
\text { duas vezes ao dia } \\
\text { por } 10 \text { dias }\end{array}$ & $\begin{array}{l}\text { (i) reação em cadeia da } \\
\text { polimerase em tempo real } \\
\text { (RT-PCR) para medir } \\
\text { RNAs virais de COVID- } \\
\text { 19, (ii) tomografia } \\
\text { computadorizada de } \\
\text { pulmão (TC) para avaliar a } \\
\text { melhora da nova } \\
\text { pneumonia por coronavírus } \\
\text { (NCP) e (iii) tempo de } \\
\text { hospitalização para avaliar } \\
\text { a recuperação do paciente. }\end{array}$ & $\begin{array}{l}\text { Grupo HCQ: } 10 \\
\text { Grupo Lopinavir/Ritonavir } \\
12 \\
\text { No } 14^{\circ} \text { dia a taxa de } \\
\text { incidência de melhora } \\
\text { pulmonar com base na TC } \\
\text { do grupo Cloroquina foi } \\
\text { mais do que dobrado em } \\
\text { relação ao grupo } \\
\text { Lopinavir/Ritonavir (razão } \\
\text { de taxas de 2,21, IC de } \\
\text { 95\% 0,81-6,62). } \\
\text { CONCLUSÃO: } \\
\text { Não houve diferença } \\
\text { significativa }\end{array}$ \\
\hline $\begin{array}{l}\text { Borba et al. } \\
\text { Effect of High vs Low } \\
\text { Doses of Chloroquine } \\
\text { Diphosphate as } \\
\text { Adjunctive Therapy } \\
\text { for Patients } \\
\text { Hospitalized With } \\
\text { Severe Acute } \\
\text { Respiratory Syndrome } \\
\text { Coronavirus } 2 \text { (SARS- } \\
\text { CoV-2) Infection A } \\
\text { Randomized Clinical } \\
\text { Trial }\end{array}$ & $\begin{array}{l}\text { Ensaio clínico } \\
\text { controlado, } \\
\text { randomizado, } \\
\text { duplo-cego }\end{array}$ & $\begin{array}{l}81 \text { pacientes } \\
\text { randomizados } \\
40 \text { pacientes alocados } \\
\text { para o grupo CQ de } \\
\text { baixa dosagem } \\
41 \text { pacientes alocados } \\
\text { para o grupo CQ de alta } \\
\text { dosagem }\end{array}$ & $\begin{array}{l}\text { Os pacientes } \\
\text { foram alocados } \\
\text { para receber CQ } \\
\text { de alta dosagem } \\
\text { (ou seja, 600mg } \\
\text { CQ duas vezes ao } \\
\text { dia por } 10 \text { dias) ou } \\
\text { CQ de baixa } \\
\text { dosagem (isto é, } \\
\text { 450mg duas vezes } \\
\text { ao dia no dia } 1 \text { e } \\
\text { uma vez ao dia } \\
\text { por } 4 \text { dias). }\end{array}$ & $\begin{array}{l}\text { O desfecho primário foi a } \\
\text { redução da letalidade em } \\
\text { pelo menos } 50 \% \text { no grupo } \\
\text { de alta dosagem em } \\
\text { comparação com o grupo } \\
\text { de baixa dosagem. }\end{array}$ & $\begin{array}{l}\text { O RNA viral foi detectado } \\
\text { em } 31 \text { de } 40(77,5 \%) \text { e } 31 \\
\text { de } 41(75,6 \%) \text { pacientes } \\
\text { nos grupos de baixa } \\
\text { dosagem e alta dosagem, } \\
\text { respectivamente. } \\
\text { A letalidade foi de } 39,0 \% \\
\text { no grupo de alta dosagem } \\
\text { (16 de 41) e de } 15,0 \% \text { no } \\
\text { grupo de baixa dosagem (6 } \\
\text { de } 40) \text {. } \\
\text { CONCLUSÃO: } \\
\text { Não houve diferença } \\
\text { significativa }\end{array}$ \\
\hline $\begin{array}{l}\text { Chen j et al. } \\
\text { La hidroxicloroquina } \\
\text { no reduciría la } \\
\text { portación viral del } \\
\text { nuevo coronavirus } \\
(\text { COVID-19) }\end{array}$ & $\begin{array}{l}\text { Ensaio clínico } \\
\text { controlado } \\
\text { randomizado }\end{array}$ & $\begin{array}{l}30 \text { pacientes adultos com } \\
\text { diagnóstico de COVID- } \\
19 . \\
\text { O grupo controle } \\
\text { recebeu tratamento } \\
\text { padrão. }\end{array}$ & $\begin{array}{l}\text { Sulfato de } \\
\text { hidroxicloroquina } \\
400 \text { mg por dia } \\
\text { durante } 5 \text { dias. }\end{array}$ & $\begin{array}{l}\text { A presença do vírus em } \\
\text { PCR de secreções } \\
\text { respiratórias foi avaliada } \\
\text { com coletas consecutivas } \\
\text { até que fosse obtido } \\
\text { resultado negativo. } \\
\text { Mortalidade, eventos } \\
\text { adversos e alterações na } \\
\text { tomografia pulmonar } \\
\text { também foram relatados. }\end{array}$ & $\begin{array}{l}\text { PCR negativa no } 7^{\circ} \text { dia: } \\
\text { 13/15 no grupo HCQ e } \\
\text { 14/15 no grupo controle. } \\
\text { CONCLUSÃO: } \\
\text { p=0,54 } \\
\text { Não houve diferença } \\
\text { significativa }\end{array}$ \\
\hline $\begin{array}{l}\text { Chen Zhaowei et al. } \\
\text { Efficacy of } \\
\text { hydroxychloroquine in } \\
\text { patients with COVID- } \\
\text { 19: results of a } \\
\text { randomized clinical } \\
\text { trial }\end{array}$ & $\begin{array}{l}\text { Ensaio clínico } \\
\text { controlado } \\
\text { randomizado }\end{array}$ & $\begin{array}{l}62 \text { pacientes com } \\
\text { COVID-19 foram } \\
\text { randomizados em: (i) } \\
\text { grupo HCQ ( } 400 \mathrm{mg} / \mathrm{d}) \\
-31 \text { pacientes; (ii) grupo } \\
\text { controle tratamento } \\
\text { convencional sem HCQ } \\
-31 \text { pacientes }\end{array}$ & $\begin{array}{l}\text { 5-dias HCQ (400 } \\
\mathrm{mg} / \mathrm{d})\end{array}$ & $\begin{array}{l}\text { O tempo para recuperação } \\
\text { clínica (TTCR), as } \\
\text { características clínicas e os } \\
\text { resultados radiológicos } \\
\text { foram avaliados no início } \\
\text { do estudo e } 5 \text { dias após o } \\
\text { tratamento para avaliar o } \\
\text { efeito do HCQ. }\end{array}$ & $\begin{array}{l}\text { uma proporção maior de } \\
\text { pacientes com pneumonia } \\
\text { melhorada no grupo de } \\
\text { tratamento HCQ }(80,6 \% \text {, } \\
25 \text { de } 31) \text { em comparação } \\
\text { com o grupo de controle } \\
(54,8 \%, 17 \text { de } 31) \text {. } \\
\text { CONCLUSÃO: } \\
\text { valor de p=0,0476 } \\
\text { Houve diferença } \\
\text { significativa entre os } \\
\text { grupos }\end{array}$ \\
\hline
\end{tabular}




\begin{tabular}{|c|c|c|c|c|c|}
\hline $\begin{array}{l}\text { Gautret et al. } \\
\text { Clinical and } \\
\text { microbiological effect } \\
\text { of a combination of } \\
\text { hydroxychloroquine } \\
\text { and azithromycin in } 80 \\
\text { COVID-19 patients } \\
\text { with at least a six-day } \\
\text { follow up: A pilot } \\
\text { observational study }\end{array}$ & $\begin{array}{l}\text { Ensaio clínico } \\
\text { aberto não } \\
\text { randomizado }\end{array}$ & $\begin{array}{l}36 \text { pacientes ( } 20 \\
\text { pacientes tratados com } \\
\text { hidroxicloroquina e } 16 \\
\text { pacientes controle). }\end{array}$ & $\begin{array}{l}200 \text { mg de sulfato } \\
\text { de HCQ oral, três } \\
\text { vezes por dia } \\
\text { durante dez dias, } \\
\text { combinado com } \\
\text { azitromicina ( } 500 \\
\text { mg em D1 } \\
\text { seguido de } 250 \\
\text { mg por dia } \\
\text { durante os quatro } \\
\text { dias seguintes). }\end{array}$ & $\begin{array}{l}\text { Pacientes com duas } \\
\text { amostras sucessivas de } \\
\text { nasofaringe negativas } \\
\text { resultantes do ensaio de } \\
\text { PCR (valor de } C T \geq 35 \text { ) } \\
\text { receberam alta. }\end{array}$ & $\begin{array}{l}\text { Pacientes tratados com } \\
\text { hidroxicloroquina }(\mathrm{N}=20) \\
\text { Pacientes controle }(\mathrm{N}=16) \\
\text { Tempo entre o início dos } \\
\text { sintomas e a inclusão } \\
\text { (dias): } \\
\text { Pacientes tratados com } \\
\text { HCQ: } 4.1 \pm 2.6 \\
\text { Pacientes controle: } 3.9 \pm \\
2.8 \\
\text { CONCLUSÃO: } \\
\text { p-valor } 0,88 \\
\text { Não houve diferença } \\
\text { significativa }\end{array}$ \\
\hline $\begin{array}{l}\text { Horby et al. } \\
\text { Effect of } \\
\text { Hydroxychloroquine } \\
\text { in Hospitalized } \\
\text { Patients with COVID- } \\
\text { 19: Preliminary results } \\
\text { from a multi-centre, } \\
\text { randomized, controlled } \\
\text { trial. }\end{array}$ & $\begin{array}{l}\text { Ensaio clínico } \\
\text { controlado, } \\
\text { randomizado, } \\
\text { aberto }\end{array}$ & $\begin{array}{l}1561 \text { pacientes alocados } \\
\text { aleatoriamente. } \\
\text { No grupo HC, } 418 \\
(26,8 \%) \text { pacientes } \\
\text { alocados. } \\
\text { No grupo de cuidados } \\
\text { usuais } 788(25,0 \%) \\
\text { pacientes alocados. }\end{array}$ & $\begin{array}{l}\text { Dose de ataque de } \\
4 \text { comprimidos } \\
(800 \mathrm{mg}) \text { em zero } \\
\text { e } 6 \text { horas, seguido } \\
\text { por } 2 \\
\text { comprimidos ( } 400 \\
\text { mg) começando } \\
12 \text { horas após a } \\
\text { dose inicial e, em } \\
\text { seguida, a cada } 12 \\
\text { horas pelos } \\
\text { próximos } 9 \text { dias. }\end{array}$ & $\begin{array}{l}\text { O desfecho primário foi a } \\
\text { mortalidade por todas as } \\
\text { causas. Os desfechos } \\
\text { secundários foram tempo } \\
\text { de alta hospitalar e, entre } \\
\text { os pacientes que não } \\
\text { estavam em ventilação } \\
\text { mecânica invasiva na } \\
\text { randomização, ventilação } \\
\text { mecânica invasiva } \\
\text { (incluindo oxigenação por } \\
\text { membrana extra corporal) } \\
\text { ou morte. }\end{array}$ & $\begin{array}{l}418(26,8 \%) \text { pacientes } \\
\text { alocados com HCQ ados } \\
\text { usuais morreram dentro de } \\
28 \text { dias (razão de taxa } 1,09 ; \\
\text { intervalo de confiança de } \\
95 \% \text { [IC] } 0,96-1,23 ; \mathrm{p}= \\
0,18) . \\
\text { CONCLUSÃO: } \mathrm{p}=0,18 ; \\
\text { Não houve diferença } \\
\text { significativa }\end{array}$ \\
\hline $\begin{array}{l}\text { Mitja et al. } \\
\text { Hydroxychloroquine } \\
\text { for Early Treatment of } \\
\text { Adults with Mild } \\
\text { Covid-19: A } \\
\text { Randomized- } \\
\text { Controlled Trial }\end{array}$ & $\begin{array}{l}\text { Ensaio clínico } \\
\text { controlado } \\
\text { randomizado }\end{array}$ & $\begin{array}{l}\text { Um total de } 293 \\
\text { pacientes foram elegíveis } \\
\text { para análise para } \\
\text { tratamento. } 157 \text { no braço } \\
\text { de controle e } 136 \text { no } \\
\text { braço de intervenção. }\end{array}$ & $\begin{array}{l}\text { Os pacientes } \\
\text { foram designados } \\
\text { para receber HCQ } \\
\text { ( } 800 \text { mg no dia } 1 \text {, } \\
\text { seguido de } 400 \\
\text { mg uma vez ao } \\
\text { dia por } 6 \text { dias) ou } \\
\text { nenhum } \\
\text { tratamento } \\
\text { antiviral (não } \\
\text { controlado com } \\
\text { placebo). }\end{array}$ & $\begin{array}{l}\text { Os resultados do estudo } \\
\text { foram a redução da carga } \\
\text { de RNA viral em } \\
\text { esfregaços nasofaríngeos } \\
\text { até } 7 \text { dias após o início do } \\
\text { tratamento }\end{array}$ & $\begin{array}{l}\text { Não foram encontradas } \\
\text { diferenças significativas na } \\
\text { redução média da carga } \\
\text { viral no dia } 3 \text { ( }-1,41 \text { vs. - } \\
1,41 \text { Log } 10 \text { cópias / mL no } \\
\text { braço de controle e } \\
\text { intervenção, } \\
\text { respectivamente; diferença } \\
0,01 \text { [IC } 95 \% \text {-0,28; } 0,29]) \\
\text { ou no dia } 7 \text { (-3,37 vs. - } \\
3,44 ; \text { d -0,07 [-0,44; } 0,29]) \text {. } \\
\text { Este regime de tratamento } \\
\text { não reduziu o risco de } \\
\text { hospitalização ( } 7,1 \%, \\
\text { controle vs. } 5,9 \%, \\
\text { intervenção; RR } 0,75 \\
[0,32 ; 1,77]) \text { nem encurtou } \\
\text { o tempo para a resolução } \\
\text { completa dos sintomas (12 } \\
\text { dias, controle vs. } 10 \text { dias, } \\
\text { intervenção; p = } 0,38) \text {. } \\
\text { CONCLUSÃO: p=0,38 } \\
\text { Não houve diferença } \\
\text { significativa }\end{array}$ \\
\hline $\begin{array}{l}\text { Skipper et al. } \\
\text { Hydroxychloroquine } \\
\text { in Nonhospitalized } \\
\text { Adults With Early } \\
\text { COVID-19. A } \\
\text { Randomized Trial. }\end{array}$ & $\begin{array}{l}\text { Ensaio clínico } \\
\text { controlado, } \\
\text { randomizado, } \\
\text { duplo-cego }\end{array}$ & $\begin{array}{l}\text { De } 491 \text { pacientes dos } \\
\text { quais } 423 \text { contribuíram } \\
\text { com dados de desfecho } \\
\text { primário. Destes, } 341 \\
(81 \%) \text { tinham } \\
\text { confirmação laboratorial } \\
\text { com SARS-CoV-2 ou } \\
\text { exposição } \\
\text { epidemiologicamente } \\
\text { ligada a uma pessoa com } \\
\text { infecção confirmada por } \\
\text { laboratório; } 56 \% \text { (236 de } \\
423 \text { ) foram inscritos } \\
\text { dentro de } 1 \text { dia do início } \\
\text { dos sintomas. A } \\
\text { mudança na gravidade } \\
\text { dos sintomas ao longo de } \\
14 \text { dias não diferiu entre } \\
\text { os grupos HCQ e } \\
\text { placebo (diferença na }\end{array}$ & $\begin{array}{l}\text { Hidroxicloroquina } \\
\text { oral ( } 800 \text { mg uma } \\
\text { vez, seguido de } \\
600 \text { mg em } 6 \text { a } 8 \\
\text { horas, depois } 600 \\
\text { mg diariamente } \\
\text { por mais } 4 \text { dias) } \\
\text { ou placebo } \\
\text { mascarado. }\end{array}$ & $\begin{array}{l}\text { Sintomas e gravidade no } \\
\text { início e depois nos dias } 3 \text {, } \\
5,10 \text { e } 14 \text {, usando uma } \\
\text { escala visual analógica de } \\
10 \text { pontos. O desfecho } \\
\text { primário foi a mudança na } \\
\text { gravidade geral dos } \\
\text { sintomas ao longo de } 14 \\
\text { dias. }\end{array}$ & $\begin{array}{l}\text { A mudança na gravidade } \\
\text { dos sintomas ao longo de } \\
14 \text { dias não diferiu entre os } \\
\text { grupos hidroxicloroquina e } \\
\text { placebo (diferença na } \\
\text { gravidade dos sintomas: } \\
\text { relativa, } 12 \% \text {; absoluta, - } \\
0,27 \text { pontos [IC 95\%, -0,61 } \\
\text { a } 0,07 \text { pontos]; } P=0,117 \text { ). } \\
\text { CONCLUSÃO: } \\
\text { p=0,117 } \\
\text { Não houve diferença } \\
\text { significativa. }\end{array}$ \\
\hline
\end{tabular}




\begin{tabular}{|c|c|c|c|c|c|}
\hline & & $\begin{array}{l}\text { gravidade dos sintomas: } \\
\text { relativa, } 12 \% \text {; absoluta, - } \\
0,27 \text { pontos [IC } 95 \%,- \\
0,61 \text { a } 0,07 \text { ponto]. }\end{array}$ & & & \\
\hline $\begin{array}{l}\text { Tang et al. } \\
\text { Hydroxychloroquine } \\
\text { in patients mainly with } \\
\text { mild to moderate } \\
\text { COVID-19: an open-- } \\
\text { label, randomized, } \\
\text { controlled trial }\end{array}$ & $\begin{array}{l}\text { Ensaio clínico } \\
\text { controlado } \\
\text { randomizado, } \\
\text { aberto }\end{array}$ & $\begin{array}{l}150 \text { pacientes } \\
\text { hospitalizados com } \\
\text { COVID - } 19 \\
\text { confirmados } \\
\text { laboratorialmente. } \\
75 \text { pacientes foram } \\
\text { atribuídos ao HCQ mais } \\
\text { tratamento padrão } \\
\text { (SOC) e } 75 \text { para SOC } \\
\text { sozinho. }\end{array}$ & $\begin{array}{l}\text { HCQ foi } \\
\text { administrado com } \\
\text { uma dose de } \\
\text { ataque de } 1,200 \\
\text { mg por dia } \\
\text { durante três dias, } \\
\text { seguida por uma } \\
\text { dose mantida de } \\
800 \text { mg por dia } \\
\text { durante os dias } \\
\text { restantes (duração } \\
\text { total do } \\
\text { tratamento: } 2 \text { ou } 3 \\
\text { semanas para } \\
\text { pacientes leves / } \\
\text { moderados ou } \\
\text { graves, } \\
\text { respectivamente). }\end{array}$ & $\begin{array}{l}\text { O desfecho primário foi se } \\
\text { os participantes tiveram } \\
\text { uma conversão negativa de } \\
\text { SARS - CoV - } 2 \text { em } 28 \\
\text { dias e foi analisado de } \\
\text { acordo com o princípio da } \\
\text { intenção de tratar. }\end{array}$ & $\begin{array}{l}\text { Entre } 150 \text { pacientes, } 148 \\
\text { apresentavam doença leve } \\
\text { a moderada e } 2 \\
\text { apresentavam doença } \\
\text { grave. A diferença entre os } \\
\text { grupos foi de } 4,1 \% \text { (IC } \\
95 \%-10,3 \% \text { a } 18,5 \%) \text {. Na } \\
\text { população de segurança, } \\
\text { eventos adversos foram } \\
\text { registrados em } 7 \text { ( } 8,8 \%) \\
\text { não receptores de HCQ (N } \\
=80 \text { ) e em } 21 \text { (30\%) } \\
\text { receptores de HCQ (N = } \\
70) \text {. } \\
\text { CONCLUSÃO: } \\
\text { Não houve benefício } \\
\text { adicional. }\end{array}$ \\
\hline $\begin{array}{l}\text { Abella et al. } \\
\text { Efficacy and Safety of } \\
\text { Hydroxychloroquine } \\
\text { vs Placebo for Pre- } \\
\text { exposure SARS-CoV- } \\
2 \text { Prophylaxis Among } \\
\text { Health Care Workers }\end{array}$ & $\begin{array}{l}\text { Ensaio clínico } \\
\text { controlado, } \\
\text { randomizado, } \\
\text { duplo-cego }\end{array}$ & $\begin{array}{l}\text { O ensaio randomizou } \\
132 \text { profissionais de } \\
\text { saúde em tempo integral } \\
\text { em hospitais (médicos, } \\
\text { enfermeiras, assistentes } \\
\text { de enfermagem } \\
\text { certificados, técnicos de } \\
\text { emergência e terapeutas } \\
\text { respiratórios), dos quais } \\
125 \text { eram inicialmente } \\
\text { assintomáticos e tiveram } \\
\text { resultados negativos para } \\
\text { SARS-CoV-2 por swab } \\
\text { nasofaríngeo. }\end{array}$ & $\begin{array}{l}\text { Hidroxicloroquina } \\
, 600 \mathrm{mg}, \\
\text { diariamente, ou } \\
\text { placebo de } \\
\text { tamanho } \\
\text { correspondente } \\
\text { tomado por via } \\
\text { oral por } 8 \\
\text { semanas. }\end{array}$ & $\begin{array}{l}\text { O desfecho primário foi a } \\
\text { incidência de infecção por } \\
\text { SARS-CoV-2 conforme } \\
\text { determinado por um swab } \\
\text { nasofaríngeo durante as } 8 \\
\text { semanas de tratamento. Os } \\
\text { desfechos secundários } \\
\text { incluíram efeitos adversos, } \\
\text { interrupção do tratamento, } \\
\text { presença de anticorpos } \\
\text { SARS-CoV-2, frequência } \\
\text { de prolongamento do QTc } \\
\text { e resultados clínicos para } \\
\text { participantes positivos para } \\
\text { SARS-CoV-2. }\end{array}$ & $\begin{array}{l}\text { Taxa de Infecção no grupo } \\
\text { HCQ: } 4 \text { de } 64[6,3 \%] \text { Taxa } \\
\text { de Infecção no grupo } \\
\text { placebo } 4 \text { de } 61[6,6 \%] ; \text { p> } \\
0,99 \text {. } \\
\text { CONCLUSÃO: } \\
\text { p=0,99 } \\
\text { Não houve diferença } \\
\text { significativa }\end{array}$ \\
\hline $\begin{array}{l}\text { Cavalcanti et al. } \\
\text { Hydroxychloroquine } \\
\text { with or without } \\
\text { Azithromycin in Mild- } \\
\text { to-Moderate Covid-19 }\end{array}$ & $\begin{array}{l}\text { Ensaio clínico } \\
\text { controlado, } \\
\text { randomizado, } \\
\text { aberto }\end{array}$ & $\begin{array}{l}\text { Um total de } 667 \\
\text { pacientes foram } \\
\text { submetidos à } \\
\text { randomização; } 504 \\
\text { pacientes confirmaram } \\
\text { Covid-19 e foram } \\
\text { incluídos na análise de } \\
\text { intenção de tratar } \\
\text { modificada. }\end{array}$ & $\begin{array}{l}\text { Os pacientes } \\
\text { foram designados } \\
\text { aleatoriamente em } \\
\text { uma proporção de } \\
\text { 1: 1: 1 para } \\
\text { receber tratamento } \\
\text { padrão, tratamento } \\
\text { padrão mais } \\
\text { hidroxicloroquina } \\
\text { na dose de } 400 \mathrm{mg} \\
\text { duas vezes ao dia } \\
\text { ou tratamento } \\
\text { padrão mais } \\
\text { hidroxicloroquina } \\
\text { na dose de } 400 \mathrm{mg} \\
\text { duas vezes ao dia } \\
\text { mais azitromicina } \\
\text { na dose de } 500 \mathrm{mg} \\
\text { uma vez ao dia } \\
\text { durante } 7 \text { dias. }\end{array}$ & $\begin{array}{l}\text { O desfecho primário foi o } \\
\text { estado clínico em } 15 \text { dias, } \\
\text { conforme avaliado com o } \\
\text { uso de uma escala ordinal } \\
\text { de sete níveis (com níveis } \\
\text { variando de um a sete e } \\
\text { pontuações mais altas } \\
\text { indicando uma condição } \\
\text { pior) na população de } \\
\text { intenção de tratar } \\
\text { modificada (pacientes com } \\
\text { uma diagnóstico } \\
\text { confirmado de Covid-19). } \\
\text { A segurança também foi } \\
\text { avaliada. }\end{array}$ & $\begin{array}{l}\text { HCQ + AZT vs. Controle: } \\
\text { OR=0,99; CI= de } 95 \%, \\
0,57 \text { a } 1,73 ; \mathrm{P}=1,00 \\
\text { HCQ + AZT vs. } \\
\text { hidroxicloroquina sozinha: } \\
\text { OR, } 0,82 ; \mathrm{IC} \text { de } 95 \%, 0,47 \\
\text { a } 1,43 ; \mathrm{P}=1,00 . \\
\text { CONCLUSÃO: } \\
\text { p=1,00 } \\
\text { Não houve diferença } \\
\text { significativa }\end{array}$ \\
\hline $\begin{array}{l}\text { Lyngbakken et al. } \\
\text { A pragmatic } \\
\text { randomized controlled } \\
\text { trial reports lack of } \\
\text { efficacy of } \\
\text { hydroxychloroquine } \\
\text { on coronavirus disease } \\
2019 \text { viral kinetics }\end{array}$ & $\begin{array}{l}\text { Ensaio clínico } \\
\text { controlado } \\
\text { randomizado }\end{array}$ & $\begin{array}{l}53 \text { pacientes, } 27 \text { foram } \\
\text { randomizados para } \\
\text { sulfato de } \\
\text { hidroxicloroquina além } \\
\text { do tratamento padrão e } \\
26 \text { pacientes para } \\
\text { tratamento padrão } \\
\text { sozinho hospitalizados } \\
\text { com doença coronavírus } \\
\text { em } 2019 \text { (COVID-19) }\end{array}$ & $\begin{array}{l}\text { terapia com } \\
\text { hidroxicloroquina } \\
\text { (na dose de } 400 \\
\text { mg duas vezes ao } \\
\text { dia por sete dias) }\end{array}$ & $\begin{array}{l}\text { A taxa de redução da carga } \\
\text { viral SARS-CoV-2 }\end{array}$ & $\begin{array}{l}\text { A taxa de redução da carga } \\
\text { viral de SARS-CoV-2 foi } \\
\text { de } 0,24 \text { no grupo da HCQ e } \\
0,14(95 \% \text { CI }-0,10 \text { a } 0,37) \\
\text { no grupo de tratamento } \\
\text { padrão (diferença da taxa } \\
\text { de redução entre os grupos } \\
0,11 \text { [IC } 95 \% \text { - } 0,21 \text { a } 0,43] \\
\text { log } 10 \text { cópias de RNA / mL } \\
\text { / } 24 \text { h. } \\
\text { CONCLUSÃO: }\end{array}$ \\
\hline
\end{tabular}




\begin{tabular}{|c|c|c|c|c|c|}
\hline & & & & & $\begin{array}{l}\mathrm{p}=0,51 \\
\text { Não houve diferença } \\
\text { significativa }\end{array}$ \\
\hline $\begin{array}{l}\text { Abd-Elsalam et al. } \\
\text { Hydroxychloroquine } \\
\text { in the Treatment of } \\
\text { COVID-19: A } \\
\text { Multicenter } \\
\text { Randomized } \\
\text { Controlled Study }\end{array}$ & $\begin{array}{l}\text { Ensaio clínico } \\
\text { controlado } \\
\text { randomizado }\end{array}$ & $\begin{array}{l}194 \text { pacientes com } \\
\text { diagnóstico confirmado } \\
\text { de COVID-19 foram } \\
\text { igualmente } \\
\text { randomizados em dois } \\
\text { braços: } 97 \text { pacientes } \\
\text { administraram HCQ } \\
\text { mais cuidado padrão } \\
\text { (grupo HCQ) e } 97 \\
\text { pacientes administraram } \\
\text { apenas cuidado padrão } \\
\text { como braço de controle } \\
\text { (grupo de controle). }\end{array}$ & $\begin{array}{l}\text { HCQ } 400 \text { mg duas } \\
\text { vezes ao dia (no } \\
\text { dia 1) seguidos de } \\
\text { comprimidos de } \\
200 \text { mg duas } \\
\text { vezes ao dia } \\
\text { adicionados ao } \\
\text { tratamento padrão } \\
\text { de cuidado } \\
\text { adotado pelo } \\
\text { Ministério da } \\
\text { Saúde egípcio por } \\
15 \text { dias. }\end{array}$ & $\begin{array}{l}\text { Considerando a } \\
\text { porcentagem de } \\
\text { recuperação como um } \\
\text { endpoint primário }\end{array}$ & $\begin{array}{l}\text { Seis pacientes }(6,2 \%) \\
\text { morreram no grupo HCQ, } \\
\text { e cinco pacientes }(5,2 \%) \\
\text { morreram no grupo } \\
\text { controle, sem qualquer } \\
\text { diferença significativa } \\
\text { entre os dois grupos (p = } \\
0,76) \text {. } \\
\text { CONCLUSÃO: } \\
\text { p=0,76 } \\
\text { Não houve diferença } \\
\text { significativa }\end{array}$ \\
\hline
\end{tabular}

$* \mathrm{AZT}=$ azitromicina; $\mathrm{CQ}=$ cloroquina; $\mathrm{HCQ}=$ hidroxicloroquina. Fonte: Autores.

Dos 14 ensaios analisados apenas um mostrou diferença significativa entre o grupo que usou HCQ e o grupo do placebo. Esse estudo teve como objetivo avaliar a eficácia de HCQ no tratamento de pacientes com COVID-19, realizado por Chen et al., foi realizado em dezembro de 2019, utilizando uma série de casos de pneumonia de etiologia ainda desconhecida que surgiu em Wuhan, Hubei, China.

\section{Discussão}

A análise dos trabalhos selecionados mostrou inicialmente uma variação quanto ao objetivo do estudo uma vez que dos 14 artigos analisados, apenas um utilizou a HCQ como medicamento profilático após a exposição a pessoas doentes, um trabalho avaliou a HCQ como droga profilática na pré-exposição, dois trabalhos estudaram a HCQ como tratamento precoce para COVID19 e os dez trabalhos restantes avaliaram a eficácia da HCQ no tratamento de pacientes já diagnosticados pela detecção do SARS-CoV-2.

Boulware et al., conduziu um ensaio clínico randomizado, duplo-cego e controlado por placebo nos Estados Unidos e em partes do Canadá, testando HCQ como profilaxia pós-exposição. Foram selecionados adultos que tiveram exposição de alto risco. No período de quatro dias após a exposição foi feita a profilaxia com HCQ pareada a um placebo. A HCQ não preveniu a doença compatível com COVID-19 ou confirmou a infecção quando usada como profilaxia pós-exposição dentro de 4 dias após a exposição (Boulware et al., 2020).

Os dois trabalhos que utilizaram a HCQ como tratamento precoce em comparação com o tratamento usual, mostraram que o tratamento precoce com HCQ falhou em reduzir a carga viral de RNA em esfregaços nasofaríngeos após 3 e 7 dias de tratamento bem como em encurtar o tempo para a resolução completa dos sintomas em adultos com COVID-19 confirmado por PCR (Mitjà et al., 2020; Skipper et al., 2020).

Vale ressaltar que um dos ensaios analisados, randomizado, duplo-cego, controlado por placebo, foi conduzido em 2 hospitais terciários urbanos, onde profissionais de saúde que lidavam diretamente com pacientes com COVID-19 foram selecionados. O estudo randomizou 132 profissionais de saúde inicialmente assintomáticos e tiveram resultados negativos para SARS-CoV-2 por swab nasofaríngeo. Apesar do ensaio ter sido encerrado cedo por não atingir a inscrição planejada de 200 participantes, o resultado foi analisado e não detectou uma redução na transmissão da SARS-CoV-2 com a administração profilática de hidroxicloroquina, e todos os participantes que contraíram a SARS-CoV-2 eram assintomáticos ou tiveram curso de doença leve com recuperação completa. O objetivo do ensaio não foi alcançado porque não foi possível recomendar o uso rotineiro de hidroxicloroquina entre profissionais de saúde para prevenir COVID-19 (Abella et al., 2020). 
O único trabalho que mostrou diferença significativa entre os efeitos da HCQ e o placebo foi o ensaio clínico randomizado publicado por Chen e colaboradores em 2020. Um dos vieses encontrados neste estudo refere-se ao desfecho do ensaio que foi baseado no tempo para a recuperação clínica (TTCR) que é definido como o retorno da temperatura corporal e alívio da tosse, mantido por mais de $72 \mathrm{~h}$. Os critérios de normalização e mitigação para tosse e para a TC de eram definidos em níveis subjetivos e observador dependente como, exacerbada, inalterada e melhorada e moderadamente (Chen et al, 2020).

Um ponto importante a ser destacado nesta discussão, diz respeito às discordâncias nas doses de medicação, biodisponibilidade e tempo de medicação, que podem ter influenciado alguns parâmetros utilizados para avaliar a eficácia das aminoquinolinas. A maioria dos estudos foram realizados nos Estados Unidos, e os outros se dividiram em Canadá, Espanha e China.

No entanto, apesar das divergências metodológicas encontradas, os desfechos de todos os estudos foram similares, indicando que a cloroquina e hidroxicloroquina e seus respectivos compostos bioativos, apresentam ineficácia à redução da mortalidade em pacientes com COVID-19.

Os estudos analisados não demonstraram eficácia da CQ e a HCQ em pacientes infectados por SARS-CoV-2, não reduzem a carga viral em pacientes tratados com esses medicamentos. Nos estudos randomizados controlados, utilizando pacientes com COVID-19 confirmado por laboratório, mostrou que não reduziu substancialmente a gravidade dos sintomas em pacientes ambulatoriais com COVID-19 inicial leve. Ou seja, nos estudos clínicos randomizados com grupo controle existentes até o momento não mostraram nenhum benefício.

Uma limitação que deve ser mencionada, diz respeito à possibilidade de artigos relevantes não terem sido incluídos porque foram publicados em língua diferente de inglês ou em fontes não indexadas nas bases de dados eletrônicas acessadas.

\section{Conclusão}

Esta revisão sistemática foi realizada na perspectiva de investigar a eficácia da hidroxicloroquina e cloroquina no tratamento de pacientes diagnosticados laboratorialmente com COVID-19. Com relação aos efeitos da intervenção sobre os pacientes, dos 14 estudos analisados, 13 não encontraram diferença significativa. Dessa forma, foi notório que o uso das aminoquinolinas não são eficazes no tratamento da COVID-19 por não reduzir a mortalidade causada por esse vírus. Assim, estudos avaliando a eficácia dos fármacos para o combate ao novo coronavírus são vitais, principalmente com a realização de ensaios clínicos que credibilizem mais esses futuros trabalhos.

\section{Referências}

Abd-Elsalam, S., Esmail, E. S., Khalaf, M., Abdo, E. F., Medhat, M. A., Ghafar, M. S. A. E., Ahmed, O. A., Soliman, S., Serangawy, G. N. \& Alboraie, M. (2020). Hydroxychloroquine in the treatment of COVID-19: a multicenter randomized controlled study. The American Journal of Tropical Medicine and Hygiene, 103(4), 1635-1639.

Abella, B. S., Jolkovsky, E. L., Biney, B. T., Uspal, J. E., Hyman, M. C., Frank, I., Hensley, S. E., Gill, S., Vogl, D. T., Maillard, I., Babushok, D. V., Huang, A. C., Nasta, S. D., Walsh, J. C., Wiletyo, E. P., Gimotty, P. A., Milone, M. C. \& Amaravadi, R. K. (2021). Efficacy and safety of hydroxychloroquine vs placebo for pre-exposure SARS-CoV-2 prophylaxis among health care workers: a randomized clinical trial. JAMA Internal Medicine, $181(2), 195-202$.

Borba, M. G. S., Val, F. F. A., Sampaio, V. S., Alexandre, M. A. A., Melo, G. C., Brito, M., Mourão, M. P. G., Brito-Sousa, J. D., Baía-da-Silva, D., Guerra, M. V. F., Hajjar, L. A., Pinto, R. C., Balieiro, A. A. S., Pacheco, A. G. F., Santos Júnior, J. D. O., Naveca, F. G., Xavier, M. S., Siqueira, A. M., Schwarzbold, A., \& Lacerda, M. V. G. (2020). Effect of high vs low doses of chloroquine diphosphate as adjunctive therapy for patients hospitalized with severe acute respiratory syndrome coronavirus 2 (SARS-CoV-2) infection: a randomized clinical trial. JAMA Network Open, 3(4), e208857.

Boulware, D. R., Pullen, M. F., Bangdiwala, A. S., Pastick, K. A., Lofgren, S. M., Okafor, E. C., Skipper, C. P., Nascene, A. A., Nicol, M. R., Abassi, M., Engen, N. W., Cheng, M. P., LaBar, D., Lother, S. A., MacKenzie, L. J., Drobot, G., Marten, N., Zarychanski, R., \& Hullsiek, K. H. (2020). A randomized trial of hydroxychloroquine as postexposure prophylaxis for Covid-19. New England Journal of Medicine, 383(6), 517-525.

Cavalcanti, A. B., Zampieri, F. G., Rosa, R. G, Azevedo, L. C. P., Veiga, V. C., Avezum, A., Damiani, L. P., Marcadenti, A., Kawano-Dourado, L., Lisboa, T., Junqueira, D. L. M., de Barros e Silva, P. G. M., Tramujas, L., Abreu-Silva, E. O., Larankeira, L. N., Soares, A. T., Echenique, L. S., Pereira, A. J., Freitas, F. G. R., \& Berwanger, O. (2020). Hydroxychloroquine with or without Azithromycin in Mild-to-Moderate Covid-19. New England Journal of Medicine, 383(21), 2041-2052. 
Chen, Z., Hu, J., Zhang, Z., Jiang, S., Han, S., Yan, D., Zhuang, R., Hu, B., \& Zhang, Z. (2020). Efficacy of hydroxychloroquine in patients with COVID-19: results of a randomized clinical trial. Medrxiv, Cold Spring Harbor Laboratory. http://dx.doi.org/10.1101/2020.03.22.20040758.

Conselho Nacional de Saúde. (2021). CNS pede que Ministério da Saúde retire publicações sobre tratamento precoce para Covid-19. http://conselho.saude.gov.br/ultimas-noticias-cns/1570-cns-pede-que-ministerio-da-saude-retire-publicacoes-sobre-tratamento-precoce-para-covid-19.

Cortegiani, A., Ingoglia, G., Ippolito, M., Giarratano, A., \& Einav, S. (2020). A systematic review on the efficacy and safety of chloroquine for the treatment of COVID-19. Journal of Critical Care, 57, 279-283. https://doi.org/10.1016/j.jcrc.2020.03.005.

Devaux, C. A., Rolain, J.-M. \& Raoult, D. (2020). ACE2 receptor polymorphism: Susceptibility to SARS-CoV-2, hypertension, multi-organ failure, and COVID19 disease outcome. J. Microbiol. Immunol. Infect. 53, 425-435. https://doi.org/10.1016/j.jmii.2020.04.015.

Estrela, C. (2018). Metodologia Científica: Ciência, Ensino, Pesquisa. Editora Artes Médicas.

Franco, J. V. A. (2020). La hidroxicloroquina no reduciría la portación viral del nuevo coronavirus (COVID-19). Evidencia, actualización en la práctica ambulatoria, 23(1), e002051.

Gautret, P., Lagier, J.-C., Parola, P., Hoang, V. T., Meddeb, L., Sevestre, J., Mailhe, M., Doudier, B., Aubry, C., Amrane, S., Seng, P., Hocquart, M., Eldin, C., Finance, J., Vieira, V. E., Tissot-Dupont, H. T., Honoré, S., Stein, A., Million, M., \& Raoult, D. (2020). Clinical and microbiological effect of a combination of hydroxychloroquine and azithromycin in 80 COVID-19 patients with at least a six-day follow up: a pilot observational study. Travel medicine and infectious disease, 34, e101663.

Geleris, J., Sun, Y., Platt, J., Zucker, J., Baldwin, M., Hripcsak, G., Labella, A., Manson, D. K., Kubin, C., Barr, G., Sobieszczyk, M. E. \& Schluger, N. W. (2020). Observational Study of Hydroxychloroquine in Hospitalized Patients with Covid-19. New England Journal of Medicine, 382(25), 2411-2418. doi:https://doi.org/10.1056/NEJMoa2012410.

Ghazy, R. M., Almaghraby, A., Shaaban, R., Kamal, A., Beshir, H., Moursi, A., Ramadan, A. \& Taha, S. H. N. (2020). A systematic review and meta-analysis on chloroquine and hydroxychloroquine as monotherapy or combined with azithromycin in COVID-19 treatment. Scientific reports, 10(1), 1-18.

Horby, P., Mafham, M., Linsell, L., Bell, J. L. Staplin, N., Emberson, J. R., Wiselka, M., Ustianowski, A., Elmahi, E., Prudon, B., Whitehouse, A., Felton, T., Williams, J., Faccenda, J., Underwood, J., Baillie, J. K., Chappell, L., Faust, S. N., Jaki, T., \& Landray, M. J. (2020). Effect of Hydroxychloroquine in Hospitalized Patients with COVID-19: Preliminary results from a multi-centre, randomized, controlled trial. MedRxiv. doi:https://doi.org/10.1101/2020.07.15.20151852.

Huang, M., Tang, T., Pengfei, P., Li, M., Ma, R., Lu, J., Shu, J., You, Y., Chen, B., Liang, J., Hong, Z., Chen, H., Kong, L., Qin, D., Pei, D., Xia, J., Jiang, S. \& Shan, H. (2020). Treating COVID-19 with chloroquine. Journal of Molecular Cell Biology, 12(4), 322-325.

Lyngbakken, M. N., Berdal, J.-E., Eskesen, A., Kvale, D., Olsen, I. C., Rueegg, C. S., Rangberg, A., Jonassen, C. M., Omland, T., Røsjø, H. \& Dalgard, O. (2020). A pragmatic randomized controlled trial reports lack of efficacy of hydroxychloroquine on coronavirus disease 2019 viral kinetics. Nature Communications, 11(1), 1-6.

Mitjà, O., Corbacho-Monné, M., Ubals, M., Tebe, C., Peñafiel, J.,Tobias, A., Ballana, E., Alemany, A., Riera-Martí, N., Pérez, C. A., Suñer C., Laporte, P., Admella, P., Mitjà, J., Clua, M., Bertran, L., Sarquella, M., Gavilán, S., Ara, J., \& Vall-Mayans, M. (2020). Hydroxychloroquine for early treatment of adults with mild Covid-19: a randomized-controlled trial. Clinical Infectious Diseases. doi:https://doi.org/10.1093/cid/ciaa1009.

Pereira, A. S., Shitsuka, D. M., Parreira, F. J., \& Shitsuka, R. (2018). Metodologia da pesquisa científica. UFSM.

Recovery Collaborative Group. (2021). Dexamethasone in hospitalized patients with Covid-19. New England Journal of Medicine, $384(8), 693-704$.

Savarino, A., Di Trani, L., Donatelli, I., Cauda, R. \& Cassone, A. (2006). New insights into the antiviral effects of chloroquine. Lancet Infect. Dis. 6, 67-69.

Skipper, C. P., Pastick, K. A., Engen, N. W., Bangdiwala, A. S., Abassi, M., Lofgren, S. M., Williams, D. A., Okafor, E. C., Pullen, M. F., Nicol, M. R., Nascene, A. A., Hullsiek, K. H., Cheng, M. P., Luke, D., Lother, S. A., MacKenzie, L. J., Drobot, G., Kelly, L. E., Schwartz, I. S, \& Boulware, D. R. (2020). Hydroxychloroquine in nonhospitalized adults with early COVID-19: a randomized trial. Annals of Internal Medicine, 173(8), 623-631.

Tang, W., Cao, Z., Han, M., Wang, Z., Chen, J., Sun, W., Wu, Y., Xiao, W., Liu, S., Chen, E., Chen, W., Wang, X., Yang, J., Lin, J., Zhao, Q., Yan, Y., Xie, Z., Li, D., Yang, Y., \& Xie, Q. (2020). Hydroxychloroquine in patients with mainly mild to moderate coronavirus disease 2019: open label, randomised controlled trial. The BMJ, 369, 1-11. doi: https://doi.org/10.1136/bmj.m1849.

Thomas, J., Kneale, D., Mckenzie, J. E., Brennan, S. E. \& Bhaumik S. (Eds.). (2019). Cochrane Handbook for Systematic Reviews of Interventions version 6.0 (Chap. 2). www.training.cochrane.org/handbook.

UNA-SUS (2021). Organização Mundial de Saúde declara pandemia do novo coronavírus. https://www.unasus.gov.br/noticia/organizacao-mundial-de-saudedeclara-pandemia-de-coronavirus.

WHO. (2020). Coronavirus disease 2019 (COVID-19), Situation report 85. https://www.who.int/docs/default-source/coronaviruse/situation-reports/20200414sitrep-85-covid-19.pdf?sfvrsn=7b8629bb_4.

WHO. (2021). Weekly Operational Update on COVID-19, Issue No. 59. https://www.who.int/publications/m/item/weekly-operational-update-on-covid-19---14june-2021.

Yan, Y., Zou, Z., Sun, Y., Li, X., Xu, K.-F., Yuquan, W., Jin, N. \& Jiang, C. (2013). Anti-malaria drug chloroquine is highly effective in treating avian influenza A H5N1 virus infection in an animal model. Cell Research, 23, 300-302. 